\title{
Opting life-saving measures to younger or the elder in the critical care centre amid covid pandemic crisis: the ethical and legal dilemma
}

\begin{abstract}
Mahanta Putul
The dreadful pandemic of Covid-19 has wrecked the worldwide population. Furthermore, the pandemic has initiated an unprecedented admission of ailing cases in the Intensive Care Unit (ICU) or Critical Care Centre (CCC), raising various ethical conflict relating to the Triage, removing life-saving supports and providing end-of-life care. Besides, the moral and ethical quandary has also increased manifold while communicating with patients and family members, including informed consent and informed refusal to the suggested treatment procedures. The acknowledgement of massive acute respiratory distress syndrome (ARDS) cases in serious form surprisingly surpassing the bed availability at the CCC in most parts of several countries. Due to this fact, four novel choices never used before were well-thought-out with the primary objective in reduction of fatality of the cases as much as possible, viz., (i) to line up the maximum number of bed at CCC for cases with the excellent outcome; (ii) to raise the number of economic bed at CCC; (iii) to arrange to shift to distant centres with more beds availability and (iv) reduction of ICU stay and the removal of life-saving measures. The hospital visit by the family members was also banned to save them from the infection. Thus, India has taken unprecedented and stern preventive measures against Covid-19 to control its spread to protect its citizens. However, as a prime component of the healthcare system, the treating physicians face a substantial legal and ethical dilemma while dealing with many patient's influxes at the CCC worldwide.
\end{abstract}

\section{BACKGROUND}

The caregivers face an ethical and legal quandary overallocating the facilities to disproportionately raised critically ill patients because of the scarcity of human resources, ICU beds, oxygen supply, and other life-saving measures, as shown in Table 1. Preventing attendant's visit to hospital has also complicated further the decades-old research outcome to improve communication with families and caregivers during this crucial period. ${ }^{1}$

Table 1 Dilemmas in patient selection

\begin{tabular}{|l|l|}
\hline S1 No & Admission to Intensive Care Unit (ICU) \\
\hline 1 & $\begin{array}{l}\text { Those patients of a young wage earner or senior } \\
\text { citizens? }\end{array}$ \\
\hline 2 & $\begin{array}{l}\text { Those patients with the excellent outcome with } \\
\text { the current illness? }\end{array}$ \\
\hline 3 & $\begin{array}{l}\text { The patient who most likely to survive for a } \\
\text { prolonged period considering their preexisting } \\
\text { illness? }\end{array}$ \\
\hline
\end{tabular}

Considering the above dilemmas, can a physician make their own choices? Then, with a bit of time in hand, the physicians make a life-saving decision to save ARDS patients based on different guidelines.

The different hospital follows different guidelines in other countries. Some hospital authorities favour saving youngsters than the elders, ${ }^{2}$ though ethically and legally it is challenging. Also, the conflicts come while the physicians are to consider some of the patient's wishes or Advance Medical Directive (AMD) at the patient's end phase of life, as shown in Table 2.

However, real-life scenarios are more challenging and painful. Many physicians argue that age should be considered as a condition for the ICU bed besides the severity of the disease. The physician feels sad for those youngers with serious ARDS though they never deny the bed for the elderly. The scene is completely different inside the ICU, yet extraordinarily complex to favour the younger over the aged. The physician prefers the young bread-earner whose outcome is expected

Cite this editorial as: Mahanta Putul. Opting life-saving measures to younger or the elder in the critical care centre amid covid pandemic crisis: the ethical and legal dilemma. Int J Health Res Medico Leg Prae 2021 JanJun;7(1):7-11. Doi: 10.31741/ijhrmlp.v7.i1.2021.1 
Table 2 Aspect that should be looked for at the time of decision making

\begin{tabular}{|l|l|}
\hline S1 No & Related to patients \\
\hline 1 & $\begin{array}{l}\text { Wishes or orders of patients, viz., "Don't } \\
\text { resuscitate", "Don't intubate", and "Allow natural } \\
\text { death" when their vital organs stop }\end{array}$ \\
\hline 2 & $\begin{array}{l}\text { Withdrawal of life supports from those whose vital } \\
\text { organ has stopped to give a chance to others who } \\
\text { are waiting for the revival }\end{array}$ \\
\hline 3 & Advance medical directives \\
\hline 4 & With severe comorbidities \\
\hline 5 & Prognosis of acute illness and expected outcomes \\
\hline 6 & The poor condition of Livingood \\
\hline 7 & Fatality Scores \\
\hline & Related to legal caretakers \\
\hline 1 & $\begin{array}{l}\text { Communication difficulties, including informed } \\
\text { consent and informed refusal }\end{array}$ \\
\hline 2 & Witness to patient's wishes \\
\hline 3 & $\begin{array}{l}\text { Interdisciplinary decision-making procedure, its } \\
\text { documentation, and family consent }\end{array}$ \\
\hline 4 & Documentation of medical record \\
\hline
\end{tabular}

over the aged one who may not survive. ${ }^{2}$ In a life-threatening condition, a grave decision must be express by the patient or attendant about the intensive resuscitation process in the event of a stoppage of their vital organs as quality relief becomes the aim of care. ${ }^{3}$

During the hospital stay, many of them express their willingness about Don't Resuscitate (DNR), Don't Intubate (DNI) and Allow Natural Death (AND). In the above circumstances, the treating physician must consider all the standing legal constraint and their validity. In addition, the family members must be asked if the patient has advance directives (ADS).

The Indian scenario has lots of legal restriction about lifeprolonging and end-of-life care measures. ${ }^{3}$ All those issues come into play if any such actions are taken in active or impending cardiorespiratory arrest cases. In medical waffle, allowing all such measures are considered "full code," while an order not to make any such procedures ${ }^{3}$ is known as a DNR wishes. These discussions are often done between severely ill patients and first-time attending physician. An open and accessible discussion on the patient's standpoint on his life, disease and procedures should be undertaken. If a patient's vital parameter deteriorates, a critical choice about actual endof-life care may follow. ${ }^{2}$

The different voluntary choices of the patients for ending their life are associated with legal issues, and they need better empathetic comprehension and clear communications. Therefore, this editorial explored the different ethical and legal queries and their practical applicability in the Indian context amid the covid pandemic crisis.

\section{Application of DNR wishes}

In DNR instruction of the patient, cardiopulmonary resuscitation (CPR) is not given while a patient suffers from a cardiorespiratory arrest. The whole procedures must be well recorded and is a recognized concept in many advanced countries. Here, nearly $15 \%$ of patients with DNR orders have undergone surgical procedures, including tracheostomy, gastrostomy, and central venous catheter insertion. ${ }^{4}$

The capable ill person or legal caretaker usually makes such orders for withdrawing precise resuscitative measures in need. Healthcare providers need to initiate strategies to handle DNR orders in anaesthesia and surgery. ${ }^{5}$ The acceptance of DNR orders increases because the people are well informed about the Patient Self-Determination Act and advanced directives. ${ }^{6}$

\section{Application of DNI wishes}

The term DNR and DNI have different choices. While a patient requests a DNR choice, the doctor must ask whether they want a DNI wish. For example, a patient may have breathing distress before the failure of the cardiovascular system. In this condition, the breathing tube is not given, but CPR may be initiated. If the breathing difficulties continue, the heart or lungs may go into full arrest. In that sense, intubation, however, may avert the arrest of lung and heart.

\section{Application of wishes of "AND"}

The term "AND" is applicable while only the pain-relieving measures are taken to get rid of pain and other symptoms. The interventions may be withdrawing resuscitation measures, nutrition supplementation, intravenous fluids, and the medications prolonging the death. The process of natural death should not be intervened. Here the only effort is made to make the patient death process relaxed and peaceable. ${ }^{7}$

The DNR process is a kind of passive mercy killing experienced in most areas of the world without any legal issues. ${ }^{8}$ But the term assisted suicide and physician-assisted suicide is not the same as that of mercy killing. ${ }^{9}$ Active mercy killing and physician-assisted suicide are prohibited in many countries, except Switzerland and the Netherlands. But many politicians and support groups for patient pressurizing to sanction this practice around Europe affect many parts of the world. ${ }^{10}$

Professional honesty is to be maintained to avoid moral conflict. In addition, distributive justice is to be served. An open discussion of options, resources, and outcomes should follow with the patient and attendant as adopted by the American College of Surgeons. ${ }^{11}$ These provide a fundamental base to create strategies to address perioperative DNR orders. 


\section{INDIAN PERSPECTIVE}

In India, the practice of DNR wishes yet to be legalized. As a result, the stately manner of living and dying has not been widely reviewed in the judiciary.

In many aspects of end-of-life care, the Indian laws are vague. The hospital expenditures of the ailing patient also play a vital role in continuing any such expensive lifeprolonging procedures. In many such situations, the patient itself or their relative is to bear all such bill. ${ }^{12}$

Practicing many such existing guidelines regarding end-oflife care is not allowed in India. Even the Hon'ble Courts of India has debated for decades to admit passive euthanasia using the removal of life-support to Aruna Shanbaug, who was in a state of permanent vegetative state for more than 37 years at King Edward Memorial Hospital. ${ }^{13}$ Some strategies have been proposed recently to off-putting life-prolonging interferences and providing quality care at the end of life in Indian critical care centres. ${ }^{14}$

However, the Hon'ble Supreme Court of India, on 2018 March 9, has legalized passive euthanasia in a landmark verdict, permitting 'living will' by patients on diminishing life-saving measures if they go to a state of irreversible coma. ${ }^{12}$ This legalization of passive euthanasia in India has recognized that a terminally ill patient or a person in PVS can execute an "advance medical directive" or a "living will" to deny lifeprolonging measures.

At times, many queries have been raised on these issues. However, many agree to the right to choose to die of the terminally ill patient, but what if the right becomes an obligation. Indian law has not given such right to end their life, so they cannot ask their doctor to stop the medication. Therefore, there is a possibility of abusing such privileges.

Many support the patient's rights. However, does this mean that we need a 'right to die' law? This subject is more legal than ethical which need extensive judicial scrutiny.

The Indian Penal Code (IPC) has covered all the issues of PAS and euthanasia. According to IPC 1860, active euthanasia is an offence under Section 302 (punishment for murder) or Section 304 (sentence for culpable homicide not amounting to murder).

Many such related issues of end-of-life care are confusing and vague in the eyes of the law, which has recently caught the interest of social media, including politicians. They argue that the treating institutes give less courtesy to those patients' wishes, especially when they face the end-of-life. Those issues will be changed only when the new laws come up legalizing active euthanasia.

Even the Hon'ble Court has intervened to manage critically ill covid patients at the CCC in recent times. The Hon'ble Supreme Court has recently taken up Suo-Moto cases and PILs from various High courts. This judicial discussion summarizes that State Government would issue guidelines so that relatives should not pressurize doctors to use Remdesivir for their relatives and doctors utilize it judiciously. The state government needs to streamline the drug distribution, and the central government ensures supply as per quota. Thus, the state government has issued guidelines for the ridiculous use and distribution of facilities equally to patients admitted in the ICU. ${ }^{2}$ Some physicians have raised questions about equal distribution of the facilities as there is a vast individual variation like age, comorbidities, disease severity, duration of illness, etc. Many treating physicians feel insecure as the doctor services are not out of legal scrutiny and litigations. Physicians have to work with the available resources with several unanswered worries, as stated in Table 3.

Table 3 Queries arises at the time of choosing treatment procedures/guidelines

\begin{tabular}{|l|l|}
\hline Query & Doctor's worries: \\
\hline 1 & $\begin{array}{l}\text { Is it mandatory to follow the available protocol } \\
\text { or guidelines laid down by the Govt. authority } \\
\text { in treating the individual patient? }\end{array}$ \\
\hline 2 & $\begin{array}{l}\text { What happens if doctors follow protocol, and } \\
\text { the patient dies? } \\
\text { Would court or state save them from charges } \\
\text { of negligence? }\end{array}$ \\
\hline 3 & $\begin{array}{l}\text { What if doctors do not follow protocol and the } \\
\text { patient survives? } \\
\text { Would allegation of overtreating and } \\
\text { overcharging stand judicial scrutiny? }\end{array}$ \\
\hline 4 & $\begin{array}{l}\text { Many other guidelines regarding its management } \\
\text { are available, which can be combined. Should a } \\
\text { PIL be filed in this regard? If so, by whom? }\end{array}$ \\
\hline 5 & $\begin{array}{l}\text { Do doctors have any immunity for alleged } \\
\text { negligence during a pandemic or natural } \\
\text { calamity? }\end{array}$ \\
\hline
\end{tabular}

Standard operative procedures (SOP) are needed to manage acute cases during the pandemic crisis. There are different protocols and SOPs for various institutes, states, and countries. Some of them are diagonally opposite, and doctors follow some protocol or others in their practice. The treating physicians are bound to follow them. In death cases, deformities and other adverse outcomes, the patients or relatives may hold the treating physicians negligent. They may even file PIL or litigate the doctor under the consumer forum, civil and criminal courts, the human right commission, and the National Medical Commission (NMC) in India. In many situations, the courts have awarded compensation and even punishments to the treating physicians.

Therefore, while the Hon'ble Courts pass any such order giving SOPs or protocol or guidelines for managing the patients, it should also clarify that they will not be negligent 
in adverse outcomes if the doctors treat patients as per protocols.

In a situation, while a patient survives, usually, there will make no litigation case. But the doctor has to justify deviating from the SOPs, like a patient not responding to management as per the SOPs. Thus, despite the excellent defence, the treating physicians are harassed by the system though proved innocent in the end. This is a kind of professional hazard the medical fraternity faced. However, the management of this Covid-19 pandemic is well covered under the Disaster Management Act 2005.

\section{NOT THE AGE BUT THE DISEASE SEVERITY A CRITERION FOR ICU BED}

Hardly few CCC have the facility for extracorporeal membrane oxygenation (ECMO) therapy for prolonging heartlung support to that patient whose both vital organs fail to function. A physician in a leading newspaper said that a 44year-old man shows a steady improvement on ECMO for $>3$ weeks. He also stated how he witnessed one young lady dying in his front due to the lack of ECMO machines support as the lone machine supporting another elderly by this time. The doctor feels helpless other than gaining stress. He said each lost life would have been saved. ${ }^{2}$

Many factors, including the patient's age and personage (V.I.P.) background, are also a matter as the doctor receives numerous calls from influential personalities. Many Non-Governmental Voluntary Organization (NGOs) have been working worldwide to help needy patients get a bed. A worker working under NGO said his struggling fact to provide a patient with an ICU bed on April 30, 2021. The patient has lost his parents the previous day, and his pregnant wife had gone for their funeral. Several political leaders and influential officers intervened on his request to give him an ICU bed. ${ }^{2}$

While facing the "once in a lifetime crisis", the physician met in the patient management were often found guardless and guard off. The critical care specialists were also caught off guard, forced to overwork. The lack of human resources, immediately non-availability of CCC beds, and their inability to transfer patients to another centre make the experience more painful, contrary to their basic ethical principles and source of immediate burden. ${ }^{15-17}$

Despite many moral, ethical, and legal difficulties, mojority treating physicians look forward with an empathic attitude. They feel disease severity as a criterion, not the age for selecting the ICU bed because of the hospital's colossal rush demanding ICU bed. Based on the same criteria, all the lifesaving measures should be continued.

In conclusion, the Ethical Principles of Justice is applicable in such situations. The assignment of degrees of urgency to illnesses to decide the order of treatment to many patients (Triage) is an accepted procedure in a mass disaster or pandemic on the principle of justice that every physician has to follow is the golden rule to avoid any legal hurdles. We need to rationalize triage policies in conjunction with ethical justifications. More importantly, the whole triage process needs to be documented.

\section{REFERENCES}

1. Davidson JE, Aslakson RA, Long AC, Puntillo KA, Kross EK, Hart J, et al. Guidelines for family-centred care in the neonatal, pediatric, and adult ICU. Crit Care Med 2017;45(1):103-28. doi: 10.1097/CCM. 00000000 00002169 .

2. Doctors' ethical dilemma: save the young or seniors? Times of India 2021 May 11; Available from: URL:http:/ /timesofindia.indiatimes.com/articleshow/ 82539363.cms? utm source=contentofinterest \&utm medium $=$ text\&utm campaign $=$ cppst

3. Mahanta Putul, Thakuria KD. End of life care: 'do not resuscitate', 'do not intubate' and 'allow natural death' ethical dilemmas. Indian Internet J Forensic Medicine Toxicology 2019 Jan-March;17(1):1-4.

4. Truog RD. "Do-not-resuscitate" orders during anaesthesia and surgery. Anaesthesiology 1991;74:6068. doi: 10.1097/00000542-199103000-00030.

5. La Puma J, Silverstein MD, Stocking CB. Lifesustaining treatment: a prospective study of patients with DNR orders in a teaching hospital. Arch Intern Med 1988;148:2193-8. doi:10.1001/archinte. 1988.00380 100067015.

6. Omnibus Budget Reconciliation Act of 1990. Title IV, Section 4206. Congressional Record, Oct. 26 1990;136:H12456-7.

7. Curesearch for children's cancer. DNR/DNI/AND. [cited 2018 June 20]; Available from: URL:https:// curesearch.org/DNR-DNI-AND

8. British Broadcasting Corporation. Ethics Guide. Euthanasia. 2014. [cited on 2018 June 20]; Available from: URL:http://www.bbc.co.uk/ethics/euthanasia/ overview/introduction.shtml

9. Chao DV, Chan NY, Chan WY. Euthanasia revisited. Fam Pract 2002;19:128-34.

10. Farooq Khan, George Tadros. Physician-assisted suicide and euthanasia in Indian context: sooner or later, the need to ponder! Indian J Psychol Med 2013 JanMar;35(1):101-105.

11. Fine PG. DNR in the OR - anesthesiologists, medical ethics, and guidelines. ASA Newsletter 1994;58:104.

12. Mani RK. Limitation of life support in the ICU: ethical issues relating to end of life care. Indian $\mathrm{J}$ Crit Care Med 2003;7:112-7. 
13. Mahanta Putul. Euthanasia: dying with dignity. The Assam Tribune 2018 March 14; editorial:6.

14. Mani RK, Amin P, Chawla R, Divatia JV, Kapadia F, Khilnani $P$, et al. Limiting life-prolonging interventions and providing palliative care towards the end of life in Indian intensive care units. Indian J Crit Care Med 2005;9:96-107.

15. White $\mathrm{DB}, \mathrm{Lo} \mathrm{B}$. A framework for rationing ventilators and critical care beds during the COVID-19 pandemic. JAMA 2020;323:1773-4.

16. Maves RC, Downar J, Dichter JR, Hick JL, Devereaux A, Geiling JA, et al. Triage of scarce critical care resources in COVID-19 an implementation guide for regional allocation. Chest 2020. [cited 2021 June 15]. Available from: URL:https://doi.org/10.1016/ j.chest.2020.03.063

17. Lai J, Ma S, Wang Y, Cai Z, Hu J, Wei N, et al. Factors associated with mental health outcomes among health care workers exposed to coronavirus disease 2019. JAMA Netw Open 2020;3(3):e203976.

\section{Address for correspondence:}

Prof (Dr.) Putul Mahanta MD, PhD

Fellow Indian Congress of Forensic Medicine and Toxicology

Fellow Indian Association of Medico-legal Expert

Editor-in-chief, IJHRMLP

Professor and Head, Forensic Medicine and Toxicology

Assam Medical College and Hospital, Dibrugarh, Assam, India

Email: editor@ijhrmlp.org

Website: www.ijhrmlp.org 